\title{
Frontières
}

\section{NADEAU, Marie-Thérèse, Que deviennent les morts?, Montréal-Paris, Médiaspaul, 2003, 141 p.}

\section{Jean-Jacques Lavoie}

Volume 16, numéro 2, printemps 2004

URI : https://id.erudit.org/iderudit/1074128ar

DOI : https://doi.org/10.7202/1074128ar

Aller au sommaire du numéro

Éditeur(s)

Université du Québec à Montréal

ISSN

1180-3479 (imprimé)

1916-0976 (numérique)

Découvrir la revue

Citer ce compte rendu

Lavoie, J.-J. (2004). Compte rendu de [NADEAU, Marie-Thérèse, Que deviennent les morts ?, Montréal-Paris, Médiaspaul, 2003, 141 p.] Frontières, 16(2), 100-100. https://doi.org/10.7202/1074128ar

Ce document est protégé par la loi sur le droit d'auteur. L'utilisation des services d'Érudit (y compris la reproduction) est assujettie à sa politique d'utilisation que vous pouvez consulter en ligne.

https://apropos.erudit.org/fr/usagers/politique-dutilisation/
Cet article est diffusé et préservé par Érudit.

Érudit est un consortium interuniversitaire sans but lucratif composé de l’Université de Montréal, l’Université Laval et l’Université du Québec à Montréal. Il a pour mission la promotion et la valorisation de la recherche. https://www.erudit.org/fr/ 


\section{NADEAU, Marie-Thérèse Que deviennent les morts?}

Montréal-Paris, Médiaspaul, 2003, $141 p$.

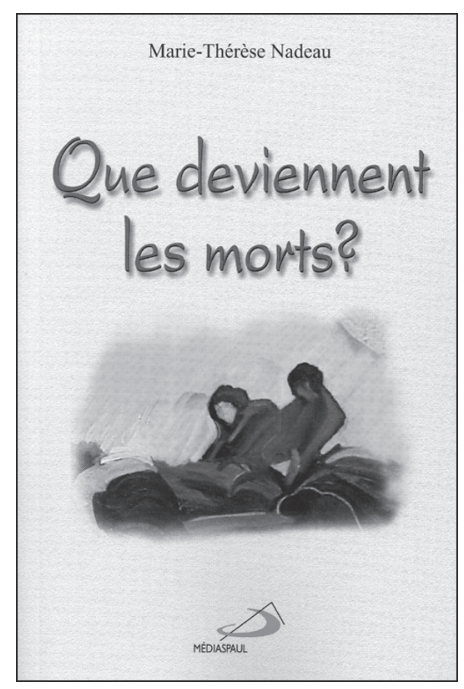

Que deviennent les morts? Pour répondre à cette question, MarieThérèse Nadeau, professeure de dogmatique au collège dominicain de philosophie et de théologie à Ottawa, divise son exposé en trois grandes parties.

La première partie, qui comporte trois chapitres, propose une lecture dite biologique ou historique de la mort. L'auteure commence par rappeler que la foi en la résurrection n'atténue en rien l'aspect inévitable et dramatique de la mort. Pour le croyant comme pour l'incroyant, la mort est ce qui donne à la vie sa plénitude. Ou, pour le dire avec les mots du philosophe V. Jankelevitch, « la mort vitale est ce qui rend passionnante la vie mortelle» (p. 29). Encore faut-il ne pas occulter la mort et être capable de la penser dans ce qu'elle a d'essentiel! Pour ce faire, les médias, bien qu'ils donnent à la population sa ration quotidienne de mort violente, ne sont d'aucune aide puisqu'ils présentent la mort non comme un phénomène naturel, mais comme une réalité lointaine, abstraite, un spectacle, un accident dont quelqu'un est responsable. Bref, dans les médias, la mort est essentiellement scandaleuse parce qu'elle aurait pu être évitée.

Intitulée "Le chrétien et la mort", la deuxième partie vise à comprendre de quelle manière la Bible aborde la mort. Le chapitre 4 montre que l'Écriture propose deux interprétations de la mort: la première considère que la mort fait partie du plan primitif de Dieu, tandis que la seconde insiste plutôt sur le fait que mort et péché se conditionnent mutuellement. Le chapitre 5 rappelle que la foi au Christ, si elle ne libère pas le croyant des lois biologiques communes, fait de la mort une croissance et non une destruction, un gain et non une perte. Selon I'auteure, dans la mort-résurrection du Christ, le désir humain trouve donc son plus parfait accomplissement.

Divisée en cinq chapitres, la troisième partie permet de poursuivre l'enquête en abordant l'au-delà de la mort. Le chapitre 6 retrace les conceptions de la vie après la mort chez les Égyptiens et les Mésopotamiens, tandis que le chapitre 7 reconstitue la genèse de l'idée d'une vie après la mort dans le Premier Testament. Plus bref, le chapitre $8 \mathrm{~s}$ 'apparente plutôt à une confession de foi en la résurrection du Christ. Par exemple, I'historien, même croyant, sera plutôt surpris de lire que "la résurrection du Christ peut être difficilement niée» (p. 97). Beaucoup plus instructif, le chapitre suivant retrace les différents langages utilisés pour exprimer l'événement de Pâques: le langage de résurrection, le langage d'exaltation et le langage de vie. Bien que ces trois langages se complètent et s'éclairent mutuellement, l'auteure est d'avis que c'est seulement avec le langage de l'exaltation que la résurrection prend son plein sens. Par ailleurs, elle conclut que le mot «recréation " semble le plus approprié pour dire la résurrection aujourd'hui. Le dernier chapitre est réservé à la question du moment de la résurrection. L'auteure passe en revue la diversité des réponses apportées par le Nouveau Testament: les croyants ressusciteront lors de la Parousie du Christ (selon les premières lettres de Paul) ou tout de suite après la mort (selon les dernières lettres de Paul) ou encore ils sont d'ores et déjà ressuscités (selon $\mathrm{Rm} 6$; Col 2; Jn $3,14-18 ; 5,24)$. Assez curieusement,
I'auteure avoue que la deuxième réponse lui semble la plus vraisemblable, mais sans dire pourquoi.

Comme il est essentiellement destiné au grand public, cet ouvrage n'offre rien de nouveau pour les spécialistes. Par conséquent, il serait déplacé d'allonger la recension en introduisant bien des points de discussion et de détail. Je me bornerai à souligner qu'il s'agit d'une introduction partielle à l'eschatologie chrétienne, qui est rédigée dans un langage simple et éclairant.

Jean-Jacques Lavoie 